\title{
Head, Neck, and Abdominopelvic Septic Thrombophlebitis: Current Evidence and Challenges in Diagnosis and Treatment
}

\author{
Luca Valerio ${ }^{1}$ Nicoletta Riva ${ }^{2}$ \\ ${ }^{1}$ Center for Thrombosis and Hemostasis, University Medical Center \\ Mainz, University of Mainz, Mainz, Germany \\ 2 Department of Pathology and Anatomy, Faculty of Medicine and \\ Surgery, University of Malta, Msida, Malta \\ Hämostaseologie 2020;40:301-310.
}

\begin{abstract}
Address for correspondence Luca Valerio, MD, Center for Thrombosis and Hemostasis, University Medical Center Mainz, University of

Mainz, Mainz, 55116, Germany (e-mail: luca.valerio@uni-mainz.de).
\end{abstract}
Abstract
Keywords
- septic thrombophlebitis
- venous thromboembolism
- Lemierre syndrome
- pylephlebitis
- bacterial infection
- anticoagulant

Septic thrombophlebitis (STP) is a complex, cross-disciplinary clinical condition that combines a localized infection with a neighboring venous thrombosis. STP can occur at several possible anatomic sites, such as dural sinuses, jugular vein (Lemierre syndrome), portal vein (pylephlebitis), and pelvic veins. Its high mortality in the preantibiotic era improved considerably with the introduction of modern antibiotics. However, little evidence exists to date to guide its clinical management. The incidence of STP or its risk factors may be increasing, and its mortality may still be considerable. These trends would have far-reaching implications, especially in the setting of increasing resistance to antimicrobial agents. No clinical assessment tools exist to support patient screening or guide treatment in STP. Few interventional studies exist on the efficacy and safety of anticoagulation. Recommendations on its indications, duration, and the agents of choice are mostly based on evidence derived from small observational studies. While all forms of STP pose similar challenges, future research may benefit from the distinction between bacteria-associated, virus-associated, and mycosisassociated thrombophlebitis. Addressing these gaps in evidence would enhance our ability to diagnose this condition and treat patients effectively.

\section{Introduction}

Septic thrombophlebitis (STP) can be defined as venous thrombosis resulting from local bacterial infection or colonization. This common pathogenesis encompasses a group of clinical conditions with specific anatomic localizations, risk factors, and prognoses.

The idea that some venous thromboses have an infectious origin originated from the observation that a thrombus may cooccur with local infection and inflammation. Historically, this pathogenesis was reflected in the anatomic-pathological demonstration of (1) perivascular inflammation and (2) vein-wall suppuration (which, together, define phlebitis) contiguous to the thrombus; (3) bacteremia; or (4) suppuration or microorganisms in the thrombus itself. ${ }^{1}$ Hence, the notion of STP. ${ }^{2}$

The bacteria themselves or the inflammation that they elicit acts on the Virchow triad's component of vascular damage. $^{3}$ Indeed, the other two components of the triad, hypercoagulability and venous stasis, often explain the association of STP with specific sites and risk factors. The oldest example is pelvic thrombophlebitis: hypercoagulability is provided by pregnancy/puerperium, stasis by the dilation of the ovarian veins. ${ }^{4}$

However, the term STP is often referred to two groups of conditions with overlapping but different etiology ( - Fig. 1 ). The first group includes thrombi resulting from vascular received

February 17, 2020

accepted after revision

May 12, 2020 (c) 2020 Georg Thieme Verlag KG Stuttgart · New York
DOI https://doi.org/

10.1055/a-1177-5127. ISSN 0720-9355. 


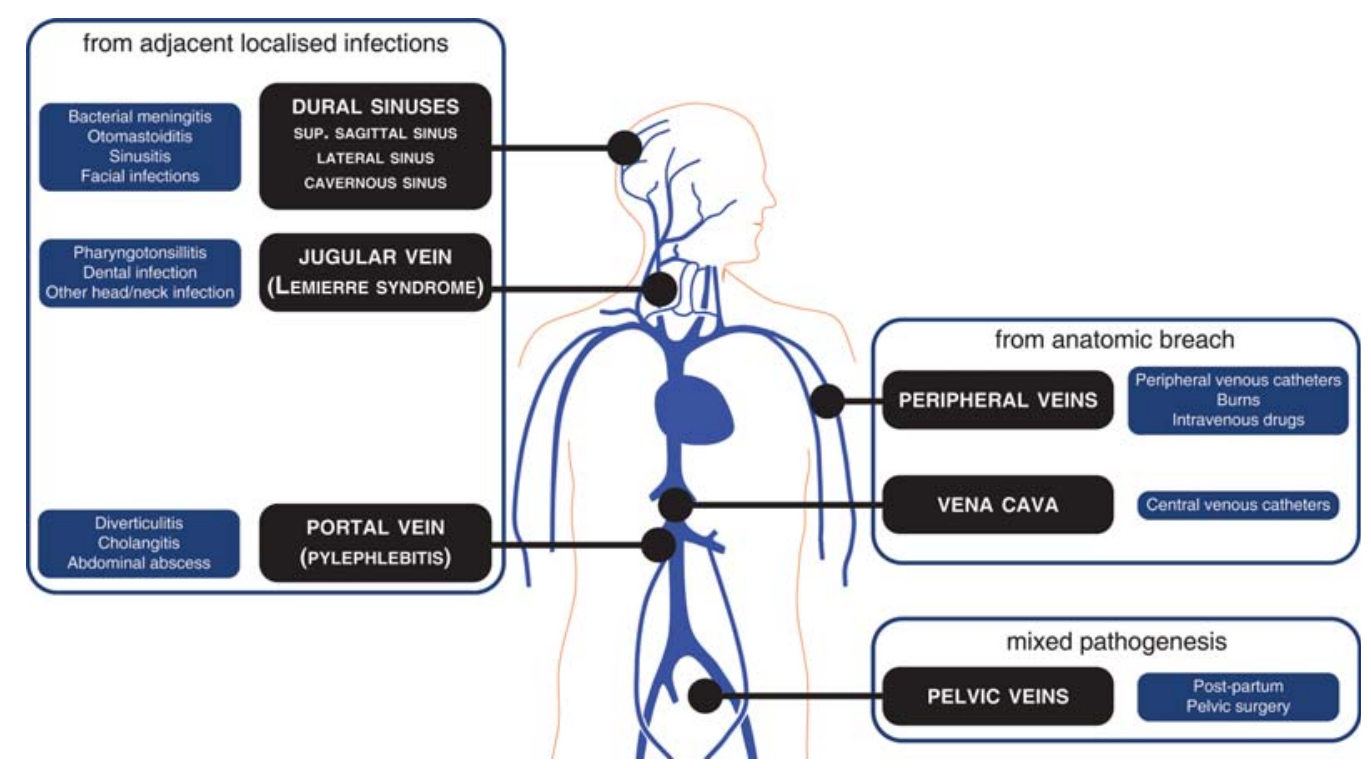

Fig. 1 Major risk factors and sites of septic thrombophlebitis.

involvement in the context of a localized infection. Dural STP can involve the sagittal sinus, the lateral sinus, or the cavernous sinus, typically as a complication of meningitis, otitis media, or facial and sinusal infections, respectively. Lemierre syndrome, a STP of the jugular vein, usually follows an acute pharyngotonsillitis in children and young adults. STP of the portal vein (pylephlebitis) is associated with abdominal infections (diverticulitis, cholangitis, appendicitis). The second group of STP includes conditions associated with septic colonization through a porte d'entrée-a breach of anatomic continuity through which bacteria enter the vascular system even in the absence of an overt primary local infection. This mechanism explains all catheter-associated thrombophlebitis, including inferior vena cava thrombosis, and peripheral vein thrombophlebitis, often found in intravenous drug users and burn patients. STP of the pelvic veins can accompany either local infections or septic colonization following delivery or surgery. Both groups may evolve into sepsis, and the distinction between infection and colonization is not always clear-cut. Yet, it sets apart catheterassociated thrombophlebitis, which affects a relatively well-defined patient population with specific implications for clinical management, and has been thus addressed by considerable research and long-standing international guidelines. $^{5}$

This article focuses on the forms of STP associated with local infection. While these conditions affect different patient populations, they are all treated in relatively similar ways and present the physician with the same management problems. Their common pathophysiology provides the rationale for a unified view of all STPs as a single entity in clinical practice. We will review available evidence and current challenges in the epidemiology and management of STP associated with head/neck, abdominal, and pelvic infections.

\section{Epidemiology}

All STPs are rare. Estimates of their incidence in the general population amount to 1 to 2 per million population-years for dural sinus $\mathrm{STP}^{6}$ and 1 per million population-years for Lemierre syndrome. ${ }^{7}$ Incidences are often produced for specific age groups at risk: the yearly incidence of dural sinus STP is then estimated to be 13 to 16 cases per million adults, ${ }^{6}$ and that of Lemierre syndrome over 10 per million children and adolescents. ${ }^{7}$ Pelvic STP has been reported to occur in 1:3,000 overall deliveries and 1:800 caesarean deliveries. $^{8}$ No reliable estimates of the incidence of pylephlebitis exist; in a single-center retrospective study, it complicated $0.6 \%$ of all intra-abdominal infections. ${ }^{9}$

\section{Pathophysiology}

Coagulation plays a defensive role during infections by limiting the dissemination of pathogens and contributing to their destruction. ${ }^{10}$ The systemic inflammatory response during sepsis includes the increased expression of procoagulant cytokines such as interleukin-1 (IL-1), IL-6, and tumor necrosis factor- $\alpha,{ }^{11}$ which also activate platelets. ${ }^{12}$ Locally, bacteria and viruses elicit a prothrombotic environment both indirectly, through endothelial damage and inflammation, ${ }^{13}$ and directly, by inducing the expression of tissue factor on monocytes and endothelial cells, ${ }^{14}$ activating the intrinsic coagulation pathway, ${ }^{10}$ inhibiting the physiologic anticoagulation mechanisms, ${ }^{15}$ and promoting platelet aggregation, ${ }^{16}$ particularly via complement activation. ${ }^{17}$ Antiphospholipid antibodies generated during bacterial and viral infections ${ }^{18}$ may result in thrombotic syndromes clinically indistinguishable from the classic antiphospholipid antibody syndrome. ${ }^{19}$ Gram-negative 
bacteria may elicit the formation of antibodies that crossreact with platelet factor 4 (PF4), possibly leading to a procoagulant state and even to "spontaneous heparin-induced thrombocytopenia."20

Thrombotic complications can derive either from the excessive activation of coagulation or from the evasion of host defenses by the pathogen. Prolonged sepsis damages endothelial cells, leading to microvascular dysfunction and loss of antithrombotic properties, ${ }^{11}$ while sepsis-associated neutrophil extracellular traps (NETs) and neutrophil-derived extracellular vesicles also contribute to coagulation activation and platelet aggregation. ${ }^{21}$ Some bacteria seem to have developed the ability to turn coagulation to their advantage. A welldocumented example is the streptococcal ability to inhibit plasminogen and use the fibrin clot to shield themselves from the immune system. ${ }^{22}$ The combination of these mechanisms ultimately results in clinically significant thrombotic phenomena such as disseminated intravascular coagulation (DIC) and local venous thrombosis in the form of STP.

\section{Diagnosis}

Unlike their risk factors, the common principles for clinical suspicion, diagnosis, and management of STPs are remarkably similar across all venous sites.

Because of its anatomical location, only cavernous sinus STP is associated with relatively specific symptoms (headache, eye swelling) and signs (diplopia), which should raise suspicion in patients with sinusitis or other facial infections. Most other forms of STP are suspected based on the persistence of fever, leucocytosis, or positive blood cultures despite appropriate antibiotic therapy in patients at risk. For Lemierre syndrome, traditionally associated with Fusobacterium spp., a positive culture of Fusobacterium from blood or pus in patients with recent pharyngotonsillitis has been used as a criterion for clinical suspicion or even diagnosis. However, this has been challenged. Fusobacteria are difficult to grow, and reports are common of patients who, despite blood cultures being negative or growing bacteria other than Fusobacterium spp., satisfy all other criteria for Lemierre syndrome. ${ }^{23}$ The absence of bacteremia should not be used to exclude pelvic STP, as blood cultures are negative in most cases. ${ }^{24}$ The main risk factor is caesarean delivery, but a 2017 case-control study of a multicenter registry of caesarean deliveries has identified potential novel risk factors, including black ethnic background, age $<20$ years, preeclampsia, and multiple gestation. ${ }^{25}$ No specific risk factors or clinical findings exist for pylephlebitis. Once most commonly associated with appendicitis and abscesses, after 2000 it has been more often reported in patients with diverticulitis and biliary infections. ${ }^{9,26}$

In cases suggestive of STP, thrombus visualization strongly supports a conclusive diagnosis. Both ultrasound and computed tomography (CT)/magnetic resonance imaging (MRI) are used, the former ensuring lower costs and larger availability, and the latter higher accuracy. The supposed recent increase in the incidence of several forms of STP may be explained by the increased use of CT/MRI and diagnosis of subclinical cases. In contrast, increased imaging specificity may have lowered the estimated incidence of some conditions. This is the case for septic pulmonary embolism as a complication of pelvic STP: its high incidence described in the 1970s may have been partly due the exclusive use of the poorly specific plain chest radiographs in the earliest diagnoses. ${ }^{27}$ While thrombus demonstration is generally required for a diagnosis of dural STP and pylephlebitis, Lemierre syndrome and pelvic STP can be diagnosed even with negative imaging tests. In Lemierre syndrome, ultrasound, readily available in emergency settings, may miss the hallmark jugular vein thrombosis. In early stages, thrombi may be fresh and poorly echogenic; in advanced stages, by the time Fusobacterium or septic emboli are found, they may have resolved. ${ }^{23}$ Pelvic STP presents even more difficulties for the radiologist: no imaging techniques identify thrombi with sufficient accuracy in the ovarian veins. They all lack sensitivity, as clots are often too small to be visible, and specificity, as small thrombi in ovarian veins can be present in healthy postpartum women. Therefore, a presumptive diagnosis can be made and even anticoagulation considered in patients in whom no thrombus has been visualized. ${ }^{8}$

\section{Treatment}

\section{Antibiotic Therapy}

The mainstay of management of STP is antibiotic therapy. The empiric regimens recommended for each form are based on the sensitivity of the bacteria that most commonly cause the underlying infection (-Table 1 ). In most cases, third to fourth-generation cephalosporins are the agent of choice. They are combined with vancomycin to target Staphylococcus aureus (dural STP), with metronidazole or clindamycin (or replaced by a carbapenem) to target anaerobes (Lemierre syndrome, pylephlebitis). As in usual stewardship, antibiotic management should be subsequently guided by blood cultures. However, several STPs are characterized by persistently negative cultures, including most cases of pelvic STP ${ }^{24}$ and a considerable minority of those of Lemierre syndrome. ${ }^{23}$ This finding poses considerable management challenges in the case of insufficient clinical response, as the only option is broadening the antibiotic coverage blindly.

\section{Interventional Treatment}

In the preantibiotic era, invasive interventions (such as venous excision or venous ligation) were often the only options for severe STP. ${ }^{23,28}$ Since the introduction of modern antibiotic therapy, surgery has been increasingly reserved for complicated cases refractory to antibiotics. ${ }^{8,23}$ Over the last few years, the successful application of endovascular therapies has been described in case reports of septic thrombosis of large-diameter veins such as the vena cava, ${ }^{29}$ but no study has systematically explored their risk-benefit profile.

\section{Anticoagulation}

The use of anticoagulation in STP is a matter of ongoing controversy. Because STP is rare, few clinical trials have been conducted, precluding the exploration of all possible efficacy 
Table 1 Common etiologic agents and treatment recommendations for septic thrombophlebitis by site

\begin{tabular}{|c|c|c|c|c|}
\hline Site & & $\begin{array}{l}\text { Common etiologic } \\
\text { agents }\end{array}$ & Empiric antibiotic therapy ${ }^{23,26,27,85}$ & Anticoagulation ${ }^{23,26,37,62}$ \\
\hline \multirow[t]{3}{*}{$\begin{array}{l}\text { Dural } \\
\text { sinuses }\end{array}$} & $\begin{array}{l}\text { Superior } \\
\text { sagittal } \\
\text { sinus }\end{array}$ & $\begin{array}{l}\text { As in bacterial meningitis: } \\
\text { Streptococcus pneumonia, } \\
\text { Neisseria meningitidis. }\end{array}$ & $\begin{array}{l}\text { Vancomycin }+3 \text { rd-4th } \\
\text { generation cephalosporin }\end{array}$ & $\begin{array}{l}\text { Not recommended because of } \\
\text { high risk of hemorrhage }\end{array}$ \\
\hline & $\begin{array}{l}\text { Lateral } \\
\text { sinus }\end{array}$ & $\begin{array}{l}\text { Proteus spp. } \\
\text { Staphylococcus aureus } \\
\text { Escherichia coli } \\
\text { Bacteroides fragilis }\end{array}$ & $\begin{array}{l}\text { Metronidazole }+3 \text { rd-4th } \\
\text { generation cephalosporin } \\
\text { OR carbapenem }\end{array}$ & $\begin{array}{l}\text { Considered in patients who fail } \\
\text { to improve clinically despite } \\
\text { antibiotics and surgical drainage }\end{array}$ \\
\hline & $\begin{array}{l}\text { Cavernous } \\
\text { sinus }\end{array}$ & $\begin{array}{l}\text { Staphylococcus aureus } \\
\text { Streptococcus spp. } \\
\text { If dental infection/sinusitis: } \\
\text { anaerobes }\end{array}$ & $\begin{array}{l}\text { If no associated dental } \\
\text { infection/sinusitis: } \\
\text { vancomycin }+3 \text { rd-4th } \\
\text { generation cephalosporin } \\
\text { If associated dental infection/sinusitis: } \\
\text { metronidazole }+3 \text { rd-4th } \\
\text { generation cephalosporin }\end{array}$ & $\begin{array}{l}\text { Early heparinization is } \\
\text { standard of care }\end{array}$ \\
\hline Jugular vein & & Fusobacterium spp. & $\begin{array}{l}\text { Beta-lactamase-resistant antibiotics } \\
\text { with anaerobic activity } \\
\text { (metronidazole, clindamycin, Tazocin) }\end{array}$ & $\begin{array}{l}\text { No consensus. Often suggested } \\
\text { for patients with thrombus } \\
\text { extension or recurrence despite } \\
\text { antibiotic therapy }\end{array}$ \\
\hline Portal vein & & $\begin{array}{l}\text { Frequently polymicrobial } \\
\text { Common: } \\
\text { Streptococcus viridans } \\
\text { Escherichia coli } \\
\text { Bacteroides fragilis }\end{array}$ & $\begin{array}{l}\text { Metronidazole }+4 \text { th } \\
\text { generation cephalosporin } \\
\text { OR piperacillin-tazobactam } \\
\text { OR ticarcillin-clavulanic acid } \\
\text { OR ampicillin-sulbactam } \\
\text { OR carbapenem }\end{array}$ & $\begin{array}{l}\text { Often suggested for patients } \\
\text { with thrombus extension or } \\
\text { recurrence despite antibiotic } \\
\text { therapy }\end{array}$ \\
\hline Pelvic veins & & $\begin{array}{l}\text { Blood cultures negative in } \\
\text { the majority of cases. } \\
\text { When positive: } \\
\text { Streptococcus spp. } \\
\text { Enterobacteriaceae } \\
\text { Anaerobes }\end{array}$ & $\begin{array}{l}\text { Vancomycin }+3 \text { rd-4th } \\
\text { generation cephalosporin }\end{array}$ & $\begin{array}{l}\text { Considered in patients with } \\
\text { clear visualization of thrombus } \\
\text { and no alternative explanation } \\
\text { for persisting symptoms }\end{array}$ \\
\hline
\end{tabular}

and safety outcomes or of subpopulations in whom benefits may overweigh risks. In this context, statements on the potential benefit of anticoagulation in a specific form of STP have often been based on questionable analogies with evidence collected in other forms. - Table 1 provides an overview of current practice at each site of STP.

One of the earliest reports of anticoagulation for any STP was the retrospective series of 46 patients with pelvic STP treated with heparin described by Josey and Staggers in $1974 .{ }^{30}$ Although noninterventional, this study guided practice until the small-scale clinical trial published by Brown et al in $1999 .^{8}$ This trial compared six patients randomized to heparin treatment in addition to standard antimicrobial therapy with eight patients with standard antimicrobial therapy only and found no difference in the duration of fever or hospitalization length. The study, however, was only powered to identify differences in the duration of fever, and did not consider several other outcomes of clinical interest, such as survival, thrombus resolution, or bleeding.

Considerable evidence exists on the use of anticoagulation for sinus vein thrombosis, which includes dural STP as a subgroup. Two small trials conducted in the $1990 \mathrm{~s}^{31,32}$ found that anticoagulation seemed to lower the overall risk of death, leading to its adoption in international guidelines. ${ }^{33}$ After 2000, two additional small trials suggested that low-molecular-weight heparin (LMWH) was superior to unfractionated heparin (UFH). ${ }^{34,35}$ Unfortunately, this evidence cannot be applied as such to the subgroup of dural STP. One of the two original trials excluded dural STP ${ }^{31}$; the two more recent trials included it, but did not provide specific results for this patient subgroup. ${ }^{34,35}$ Only two observational studies have specifically addressed anticoagulation in dural STP. A single-center analysis of 19 cases seen over 44 years suggested that heparin may reduce mortality in selected cases of septic cavernous sinus thrombosis. ${ }^{36} \mathrm{~A}$ more recent analysis of prospective data on 77 patients with dural SPT did not find evidence of adverse safety outcomes in patients treated with heparin, but the small sample size prevented firm conclusions. ${ }^{37}$

International guidelines on the management of portal vein thrombosis recommend anticoagulation in most patients, although with several exceptions and differences between countries. ${ }^{38}$ However, no studies or guidelines specifically address pylephlebitis.

Similarly, neither reliable evidence nor consensus exists on the use of anticoagulation in Lemierre syndrome. The main concern is the possible hemorrhagic transformation of the frequent peripheral septic emboli. ${ }^{7}$ A single-center retrospective study on 18 patients seen over 17 years, six of whom received at least 4 weeks of LMWH, UFH, or warfarin, found no association between anticoagulation and either radiologic thrombus resolution or bleeding. In the absence of a consensus, the general rule is often cited that anticoagulation should 
only be considered in cases of retrograde thrombus extension from the internal jugular vein to the cerebral veins. ${ }^{39}$ However, the only rationale for this rule is the analogy with lateral sinus thrombosis in children, a form of dural STP in which anticoagulation has been considered since the 1990s. ${ }^{40,41}$

\section{Prognosis}

Most STPs were first described between the end of the 19th century and the mid-20th century. At that time, therapeutic options were few and usually limited to surgical venous excision; case series published until the 1960s reported death rates close to $100 \%$. The introduction of venous ligation resulted in significantly improved survival compared with venous excision, but most of the subsequent reduction in mortality can be attributed to modern antibiotics. ${ }^{23,26,42,43}$

Along with infective endocarditis, STP is the only condition that can be complicated by septic embolism, ${ }^{44}$ especially in the case of Lemierre syndrome and pelvic STP. Unlike thromboembolism, septic embolism does not exclusively lead to venous infarct or ischemia, but can present as abscess at locations not amenable to surgical treatment, including lungs, bone and joints, soft tissue, and the central nervous system. Embolization also reflects the continuous bacterial spread in the circulation, leading to a bacteremia difficult to control by medical therapy only. As such, septic embolism poses serious treatment challenges and severely affects prognosis. Septic pulmonary embolism is considered to be particularly specific for STP, as its only alternative cause is right-sided infective endocarditis. ${ }^{45}$ As this form of embolism is most typically associated with Lemierre syndrome ${ }^{7}$ and vena cava STP, ${ }^{45}$ the diagnosis of these conditions should prompt a low index of suspicion for pulmonary involvement. Because septic pulmonary emboli can mimic lobar pneumonia, standardized radiological criteria have been proposed for their diagnosis: multiple, bilateral peripheral pulmonary nodules often with cavitations. CT can identify emboli with partial or complete abscess formation and remains more sensitive than chest X-rays. ${ }^{44}$

\section{Knowledge Gaps}

\section{Trends in the Incidence and Mortality of STPs}

Estimates on the incidence of most STPs are heterogeneous. What little information is available is limited to small case series. Inaccuracy because of rarity is compounded by detection bias in both directions. Their true incidence can be underestimated because, in clinical practice, STP is not actively searched unless several alternative diagnoses have been excluded; even when searched, it is difficult to confirm conclusively; and even when confirmed, it may not be characterized as septic, as this label rests on the concomitant finding of a systemic inflammatory reaction or a frank infection that may both be missing in mild cases or have subsided by the time the thrombus is found. Conversely, overestimation can result from small thrombi being present in patients with no clinical symptoms and having been increasingly detected as imaging techniques became more sensitive.
Several claims have been made that the incidence of dural, jugular, and portal STPs has increased over the past 30 years. ${ }^{6,7,46}$ Commonly alleged reasons include increasing bacterial antibiotic resistance or, in the case of Lemierre syndrome, strict adherence to the guidelines that limit antibiotic use in acute pharyngotonsillitis, possibly leaving some nonviral cases untreated. However, this trend is difficult to substantiate. An apparent increase in incidence may originate from higher diagnostic sensitivity (detection bias) or even an increase in published case reports (publication bias). In contrast, death rates and case fatality rates in STP series described since the 1980s have clearly decreased compared with earlier series of the 20th century. ${ }^{23,27,43}$ However, some reviews suggest that death rates are still considerable in pylephlebitis $(11 \%)^{26}$ and Lemierre syndrome (4\%). ${ }^{42}$

More detailed information on the incidence trends of STPs and their death rates or case fatality rates in the contemporary era would have far-reaching implications for both clinical practice and public health. Increasing incidence of some forms of STP would mandate changes in the empirical management of infections or prophylaxis of patients at risk: acute pharyngotonsillitis for Lemierre syndrome, ${ }^{47}$ the use of caesarean section for pelvic STP, or the management of the aging human immunodeficiency virus (HIV)infected population. ${ }^{48}$ If death rates or case fatality rates are still high, new therapeutic options should be found, as increasing antibiotic resistance may otherwise preclude further reduction.

While viruses and fungi can also be associated with thrombophlebitis, all epidemiological information on STP associated with these pathogens is limited to case reports and case series. The potential to cause clinically relevant thrombophlebitis has been attributed to both long-known viruses, such as $\mathrm{HIV},{ }^{48}$ and newly recognized ones, including COVID-19. ${ }^{49}$ As viral infections remain a difficult challenge for public health and clinical practice, international longitudinal studies are needed and should clearly distinguish STP associated with viral versus bacterial or fungal infections. This approach would also clarify whether the rarity of fungal STP reflects the rarity of mycosis, compared with bacterial or viral infections, rather than a lower thrombogenic potential of fungi. Specific analyses should address whether fungi may only be associated to thrombosis in rare, yet clinically relevant populations. ${ }^{50}$

\section{Risk Estimation and Pathogen-Specific Thrombogenic Potential}

STP is often diagnosed with a considerable delay, limiting management options and compromising patient prognosis. While the risk factors of most STPs are well known nowadays, STP is so rare that patients at risk are not systematically screened or monitored. Several STPs with no specific clinical manifestation remain a diagnosis of exclusion. This problem disproportionately affects conditions with potentially unfavorable prognosis such as cavernous sinus thrombosis from sphenoidal sinusitis, lateral sinus thrombosis from otitis media, and Lemierre syndrome after pharyngotonsillitis. 
No guidelines exist to identify those patients in whom these rare complications are likely enough to warrant additional monitoring by hospital admission or early imaging. Evidence on risk factors and epidemiology, as well as the accuracy of imaging techniques, may now be sufficient for the development of classification tools sensitive enough to identify patients with no need for monitoring or specific enough to identify those at high risk of already having developed STP. Promising candidates for inclusion in these tools could be suggested by high-quality observational data including prospectively collected data or disease registries and based on hypotheses generated by case reports or case series; they may include hypercoagulation states, immune deficiencies, and anatomic variation. An example is the alleged role of the Epstein-Barr virus (EBV) infection in the pathogenesis of Lemierre syndrome, based on small case series that cannot rule out detection bias determined by the similar age range and initial symptoms of the two conditions. ${ }^{23}$

In this perspective, the question of whether specific infectious agents cause thrombophlebitis more often than others is intriguing. This is almost certainly the case for Lemierre syndrome, which has traditionally been associated with Fusobacterium spp., and pylephlebitis, commonly caused by Bacteroides fragilis: both pathogens have been attributed marked procoagulant properties. ${ }^{51-53}$ These associations may even have implications for management choices, such as the decision to initiate anticoagulation and the type of antimicrobial agent. The impact of the pathogen on the occurrence and features of thrombophlebitis may extend to nonbacterial STP. Mycotic thrombophlebitis from Candida spp. almost exclusively involves the vena cava, ${ }^{54,55}$ but was reported also at other sites, such as the internal jugular vein. ${ }^{56}$ Similarly, not all viruses seem to be equally thrombogenic. Clinically serious thrombophlebitis has been reported in association with viral infections both acute, such as varicella zoster virus ${ }^{57-59}$ and COVID-19, ${ }^{49}$ and chronic, such as cytomegalovirus in HIV patients ${ }^{60}$ and hepatitis $\mathrm{B}$ virus. ${ }^{61}$ These considerations suggest that it would be meaningful to distinguish, in future research, three groups of STP defined by the major microbiological agents definitely or potentially associated with it: bacteria-associated thrombophlebitis, mycosis-associated thrombophlebitis, and virus-associated thrombophlebitis.

\section{Treatment Choices: Antibiotic Therapy and Anticoagulation}

While antibiotic therapy is the mainstay of the treatment of STP, recommendations are limited to the empiric regimes and subsequent reliance on antibiotic sensitivity testing. Little or no evidence supports other key aspects of management, such as the duration of therapy or the criteria for escalation: available studies either did not compare alternative durations of therapy or had no comparable endpoints.

The greatest unsolved issue is the role of and optimization of anticoagulation. No trial so far was sufficiently powered to explore all the efficacy outcomes of clinical interest: death, thrombus extension and recurrence, embolization rate, time to fever resolution, time to discharge, and possibly time to recanalization (insofar as this is clinically relevant). Safety outcomes should include not only bleeding, but also distant embolization from rupture of the primary thrombus and hemorrhagic transformation of abscesses, since these risks are often mentioned as reasons to avoid anticoagulation in STP. The decision to start anticoagulation depends on the identification of subgroups of patients in whom the benefits of anticoagulation outweigh risks, beyond the poorly substantiated rule of only considering anticoagulation in case of thrombus extension or recurrence despite antibiotic therapy. The alternative merits of different anticoagulation agents, dosages, and treatment durations should be evaluated.

This paucity of evidence results in great variation across STPs in the recommendations provided by the scientific literature. The indication for anticoagulation varies from the extreme of superior sagittal sinus thrombosis, in which anticoagulation is always contraindicated because of the high risk of bleeding, to pelvic STP, a unique case in which it is considered acceptable to start anticoagulation even without radiological evidence of thrombosis. ${ }^{62}$

Due to the important contribution of inflammation to both sepsis and venous thromboembolism, ${ }^{12,63}$ heparin may be the anticoagulant of choice in the acute phase of STP due to its intrinsic anti-inflammatory properties. ${ }^{64,65}$ It is still controversial whether nonsteroidal anti-inflammatory drugs, often used in the treatment of superficial thrombophlebitis, ${ }^{66}$ might play a role, given the increased risk of venous thromboembolism suggested by some observational studies. ${ }^{67}$

\section{Ongoing Research}

\section{Epidemiology and Clinical Outcomes}

The first results of an individual patient level analysis of all cases of Lemierre syndrome reported since $2000^{7}$ have shed light on the prognosis of this condition in the antibiotic era, revealing a possibly decreasing mortality and a still considerable burden of complications despite treatment. ${ }^{42}$ Additional analyses will provide information on the clinical profile, treatment patterns, and long-term prognosis in these patients. In addition, a systematic review aiming to clarify the role of EBV infection in the development of Lemierre syndrome is currently registered on the online PROSPERO database. $^{68}$

\section{Anticoagulation}

The EXCOA-CVT study is evaluating the optimal duration of anticoagulation in cerebral vein thrombosis. ${ }^{69}$ As the study does not formally exclude cases of infectious pathogenesis, subgroup analysis in patients with dural STP may shed light on the efficacy and safety of anticoagulation in this condition. To the best of our knowledge, no other clinical trials on the treatment of a form of STP are currently planned or ongoing.

A recent animal study has shown that the synthetic pentasaccharide fondaparinux improves survival in sepsis induced by Escherichia coli by inhibiting the activation of both the intrinsic and extrinsic coagulation pathways. ${ }^{70}$ All attempts to modulate coagulation in DIC using antithrombin, activated protein $C$, and their combination with heparins had 
so far failed because of excessive bleeding. In this setting, the advantage of fondaparinux over heparins may lie in its ability to inhibit factor Xa but not thrombin, which is necessary to generate the antithrombotic activated protein C. Future studies should further investigate the properties of fondaparinux before it is possibly considered as anticoagulant of choice in a septic or inflammatory setting.

\section{Combining Anticoagulation and Antimicrobial Activity}

Recent preclinical studies suggest that several anticoagulant agents or platelet aggregation inhibitors, as well as natural proteins involved in both coagulation and inflammation, have marked antimicrobial properties. As such, they represent viable candidates for use in STP, in which thrombosis accompanies an acute infection.

The direct thrombin inhibitor dabigatran successfully inhibited staphylococcal coagulase and was clinically safe in a randomized clinical trial in humans with staphylococcal sepsis. ${ }^{71}$ This study suggested that direct thrombin inhibitors are at least as safe as standard thromboprophylaxis with LMWH in patients with a severe infection, and provides a rationale to test the efficacy of these agents in preventing thrombus extension and septic embolization of staphylococcal STP. After clinical observations that platelet aggregation inhibitors seemed to improve survival and inflammatory biomarkers during infection, ${ }^{72,73}$ a recent study on mice has shown that ticagrelor may indeed have antimicrobial properties against several gram-negative bacteria, including multiresistant strains, and even display synergistic activity with several commonly used antibiotics. ${ }^{74}$

Similar properties are increasingly reported in several natural proteins. The hßAT isoform of antithrombin has displayed marked antibacterial properties in mice, and is depleted in the plasma of patients with severe infectious diseases. ${ }^{75}$ These findings may lead to a resurgence in the clinical application of antithrombin. In addition, in a study prompted by a previous incidental finding, the light chains of coagulation factors VII, IX, and X exhibited in vitro antibacterial activity against several gram-negative bacteria, including extensively drug-resistant pathogens. ${ }^{76}$

\section{Targeting Sepsis and Inflammation}

As sepsis and inflammation are key pathophysiological mechanisms in STP, nonanticoagulant agents that primarily act on the molecular pathways shared by sepsis, inflammation, and thrombosis may be able to modify the course of STP by either preventing thrombus formation or promoting its dissolution.

Because of the role of NETs in the development of thrombosis during sepsis, agents that prevent their formation are being explored as therapeutic options. An example of this approach is blockade of either complement factor C5a or its receptors C5aR1 and C5aR2 on neutrophils. However, complement activation seems to be more specific to infection by gram-negative than gram-positive bacteria, and some grampositive bacteria, such as $S$. aureus, are able to inhibit it. ${ }^{17}$ An alternative is pharmacologically targeting cytokines that sustain NET formation with pathways different from complement activation. Experimental blockade of interleukins IFN $\gamma$, IL-17, IL-1 $\beta$, and IL-9 reduces formation of venous thrombi in animal models. ${ }^{77}$ Recently, agonism of the adenosine $\mathrm{A} 2 \mathrm{~A}$ receptor has been shown to reduce the generation of NET and venous thrombosis mediated by antiphospholipid antibodies. ${ }^{78}$ This finding may be especially relevant to STP because of the evidence on the association between infection, antiphospholipid antibodies, and thrombosis. ${ }^{19}$

Proprotein convertase subtilisin/kexin type 9(PCSK9) inhibitors may increase the clearance of bacterial endotoxin during sepsis; at the same time, studies on knockout mice suggest that blocking PCSK9 may reduce activity against venous thrombosis. ${ }^{79}$ However, an animal study showed that neither antiPCSK9 antibodies nor germ-line deletion of pcsk9 improved mortality in mice exposed to endotoxins, ${ }^{80}$ and observational analyses have shown the relationship between endotoxinassociated inflammation and PCSK9 in humans to be complex. ${ }^{81}$ More evidence is needed before a therapeutic role for PCSK9 inhibitors in STP is considered.

Thrombus dissolution is also increasingly considered as a treatment strategy. The role of circulating inflammatory cytokines in the remodeling and resolution of venous thrombi is well established; IL-2 seems to be the most viable for testing in humans, as it is already used for other indications and is considered safe. ${ }^{77,82}$ Noncirculating molecules may also provide targets: a recent study showed that blockage of endothelin receptors prevents TGFß1-mediated thrombofibrosis and improves venous thrombus resolution in murine pulmonary circulation. This finding may be relevant to STP to the extent this pathway is involved in the endothelial dysfunction caused by a localized infection or sepsis. ${ }^{83}$ Finally, as NETs are responsible not only for thrombus formation, but also for thrombus stability, thrombus dissolution by direct targeting of NETs via DNAses has been preliminarily tested in vitro and ex vivo. ${ }^{84}$

\section{Time capsule}

We hope that

- In the next 30 years, international registries will provide accurate data on the incidence trends and the case fatality rate of septic thrombophlebitis.

- Microbiologists will be able to identify individual pathogens with high thrombogenic potential and notify the clinician upon their isolation, prompting a screening for septic thrombophlebitis in patients with refractory infection.

- In addition to anticoagulants and antibiotics, natural or synthetic compounds will provide innovative treatments that combine antimicrobial or anti-inflammatory activity with the modulation of coagulation and platelet aggregation.

- Specific guidelines will guide the indication, agent choice and duration of anticoagulant and antibiotic treatment for septic thrombophlebitis of dural sinuses, jugular vein, and portal and pelvic veins. 


\section{Authors}

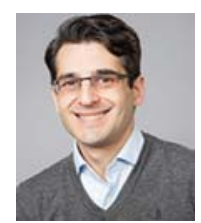

Luca Valerio graduated in Medicine at the Catholic University of Rome (Italy) and pursued a PhD in vascular epidemiology at the University of Amsterdam. In the Netherlands, he gained clinical experience in Cardiology and Emergency Medicine. He is currently based at the Center for Thrombosis and Hemostasis of the University of Mainz (Germany), where he is set to start his residency in Cardiology. His research focuses on the burden of venous thromboembolism in terms of mortality and long-term impairment, as well as on rare thromboinflammatory conditions such as Lemierre syndrome.

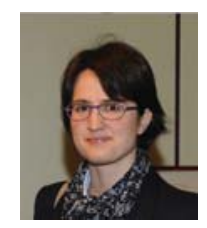

Nicoletta Riva obtained her MD at the University of Insubria in Varese (Italy), where she subsequently specialized in Internal Medicine. For several years, she has been a Research Fellow at the Research Center on Thromboembolic Disease and Antithrombotic Therapies, University of Insubria, Varese (Italy). She recently completed a PhD at the University of Malta, Msida (Malta), where she is currently a visiting lecturer with the Department of Pathology and the Department of Anatomy. Her main research interests include the prevention and treatment of usual and unusual site venous thromboembolism and the management of the anticoagulant therapy.

\section{Conflict of Interest}

The authors declare, that they have no conflict of interest.

\section{References}

1 Turner AL, Reynolds FE. Furuncle of the right nasal vestibule; septic thrombosis of the cavernous sinus; lepto-meningitis; death; autopsy. (with microscopic examination of the orbits, cavernous blood sinuses, meninges, ethmoidal and sphenoidal air sinuses). Proc R Soc Med 1926;19(Laryngol Sect):10

2 Baker CC, Petersen SR, Sheldon GF. Septic phlebitis: a neglected disease. Am J Surg 1979;138(01):97-103

3 Esmon CT. Basic mechanisms and pathogenesis of venous thrombosis. Blood Rev 2009;23(05):225-229

4 Lotze EC, Kaufman RH, Kaplan AL. Postpartum ovarian vein thrombophlebitis. Obstet Gynecol Surv 1966;21(06):853-870

5 Mermel LA, Allon M, Bouza E, et al. Clinical practice guidelines for the diagnosis and management of intravascular catheter-related infection: 2009 Update by the Infectious Diseases Society of America. Clin Infect Dis 2009;49(01):1-45

6 Silvis SM, de Sousa DA, Ferro JM, Coutinho JM. Cerebral venous thrombosis. Nat Rev Neurol 2017;13(09):555-565

7 Sacco C, Zane F, Granziera S, et al; Lemierre Study Group. Lemierre syndrome: clinical update and protocol for a systematic review and individual patient data meta-analysis. Hamostaseologie 2019;39(01):76-86

8 Brown CE, Stettler RW, Twickler D, Cunningham FG. Puerperal septic pelvic thrombophlebitis: incidence and response to heparin therapy. Am J Obstet Gynecol 1999;181(01):143-148

9 Belhassen-García M, Gomez-Munuera M, Pardo-Lledias J, et al. Pylephlebitis: incidence and prognosis in a tertiary hospital. Enferm Infecc Microbiol Clin 2014;32(06):350-354
10 Antoniak S. The coagulation system in host defense. Res Pract Thromb Haemost 2018;2(03):549-557

11 Scully M, Levi M. How we manage haemostasis during sepsis. $\mathrm{Br}$ J Haematol 2019;185(02):209-218

12 Levi M, Sivapalaratnam S. Disseminated intravascular coagulation: an update on pathogenesis and diagnosis. Expert Rev Hematol 2018;11(08):663-672

13 Branchford BR, Carpenter SL. The role of inflammation in venous thromboembolism. Front Pediatr 2018;6:142

14 Antoniak S, Mackman N. Multiple roles of the coagulation protease cascade during virus infection. Blood 2014;123(17): 2605-2613

15 Riley TV. Heparinase production by anaerobic bacteria. J Clin Pathol 1987;40(04):384-386

16 Forrester LJ, Campbell BJ, Berg JN, Barrett JT. Aggregation of platelets by Fusobacterium necrophorum. J Clin Microbiol 1985;22(02):245-249

17 Ward PA, Fattahi F. New strategies for treatment of infectious sepsis. J Leukoc Biol 2019;106(01):187-192

18 Mendoza-Pinto C, García-Carrasco M, Cervera R. Role of infectious diseases in the antiphospholipid syndrome (including its catastrophic variant). Curr Rheumatol Rep 2018;20(10):62

19 Abdel-Wahab N, Lopez-Olivo MA, Pinto-Patarroyo GP, SuarezAlmazor ME. Systematic review of case reports of antiphospholipid syndrome following infection. Lupus 2016;25(14): 1520-1531

20 Pongas G, Dasgupta SK, Thiagarajan P. Antiplatelet factor 4/heparin antibodies in patients with gram negative bacteremia. Thromb Res 2013;132(02):217-220

21 Iba T, Levi M, Levy JH. Sepsis-induced coagulopathy and disseminated intravascular coagulation. Semin Thromb Hemost 2020;46 (01):89-95

22 Frick IM, Shannon O, Neumann A, Karlsson C, Wikström M, Björck L. Streptococcal inhibitor of complement (SIC) modulates fibrinolysis and enhances bacterial survival within fibrin clots. J Biol Chem 2018;293(35):13578-13591

23 Riordan T. Human infection with Fusobacterium necrophorum (Necrobacillosis), with a focus on Lemierre's syndrome. Clin Microbiol Rev 2007;20(04):622-659

24 Dunnihoo DR, Gallaspy JW, Wise RB, Otterson WN. Postpartum ovarian vein thrombophlebitis: a review. Obstet Gynecol Surv 1991;46(07):415-427

25 Dotters-Katz SK, Smid MC, Grace MR, Thompson JL, Heine RP, Manuck T. Risk factors for postpartum septic pelvic thrombophlebitis: a multicenter cohort. Am J Perinatol 2017;34(11): $1148-1151$

26 Choudhry AJ, Baghdadi YM, Amr MA, Alzghari MJ, Jenkins DH, Zielinski MD. Pylephlebitis: a review of 95 cases. J Gastrointest Surg 2016;20(03):656-661

27 Garcia J, Aboujaoude R, Apuzzio J, Alvarez JR. Septic pelvic thrombophlebitis: diagnosis and management. Infect Dis Obstet Gynecol 2006;2006:15614

28 Weed JC. Indications and techniques of ligation of the inferior vena cava. Surg Clin North Am 1953;33(04):967-974

29 Talaie T, Drucker C, Aicher B, et al. Endovascular thrombectomy of septic thrombophlebitis of the inferior vena cava: case report and review of the literature. Vasc Endovascular Surg 2018;52(08): 641-647

30 Josey WE, Staggers SR Jr. Heparin therapy in septic pelvic thrombophlebitis: a study of 46 cases. Am J Obstet Gynecol 1974;120 (02):228-233

31 Einhäupl KM, Villringer A, Meister W, et al. Heparin treatment in sinus venous thrombosis. Lancet 1991;338(8767):597-600

32 de Bruijn SF, Stam J. Randomized, placebo-controlled trial of anticoagulant treatment with low-molecular-weight heparin for cerebral sinus thrombosis. Stroke 1999;30(03):484-488

33 Einhäupl K, Stam J, Bousser MG, et al; European Federation of Neurological Societies. EFNS guideline on the treatment of 
cerebral venous and sinus thrombosis in adult patients. Eur J Neurol 2010;17(10):1229-1235

34 Misra UK, Kalita J, Chandra S, Kumar B, Bansal V. Low molecular weight heparin versus unfractionated heparin in cerebral venous sinus thrombosis: a randomized controlled trial. Eur J Neurol 2012;19(07):1030-1036

35 Afshari D, Moradian N, Nasiri F, Razazian N, Bostani A, Sariaslani P. The efficacy and safety of low-molecular-weight heparin and unfractionated heparin in the treatment of cerebral venous sinus thrombosis. Neurosciences (Riyadh) 2015;20(04):357361

36 Southwick FS, Richardson EP Jr, Swartz MN. Septic thrombosis of the dural venous sinuses. Medicine (Baltimore) 1986;65(02): 82-106

37 Zuurbier SM, Coutinho JM, Stam J, et al; ISCVT Investigators. Clinical outcome of anticoagulant treatment in head or neck infection-associated cerebral venous thrombosis. Stroke 2016; 47(05):1271-1277

38 Wu M, Schuster M, Tadros M. Update on management of portal vein thrombosis and the role of novel anticoagulants. J Clin Transl Hepatol 2019;7(02):154-164

39 Golpe R, Marín B, Alonso M. Lemierre's syndrome (necrobacillosis). Postgrad Med J 1999;75(881):141-144

40 Doyle KJ, Jackler RK. Otogenic cavernous sinus thrombosis. Otolaryngol Head Neck Surg 1991;104(06):873-877

41 Lustig LR, Cusick BC, Cheung SW, Lee KC. Lemierre's syndrome: two cases of postanginal sepsis. Otolaryngol Head Neck Surg 1995;112(06):767-772

42 Valerio L, Zane F, Sacco C, et al. Patients with Lemierre syndrome have a high risk of new thromboembolic complications, clinical sequelae and death: an analysis of 712 cases. J Intern Med 2020 (e-pub ahead of print) . Doi: 10.1111/joim.13114

43 van der Poel NA, Mourits MP, de Win MML, Coutinho JM, Dikkers FG. Prognosis of septic cavernous sinus thrombosis remarkably improved: a case series of 12 patients and literature review. Eur Arch Otorhinolaryngol 2018;275(09):2387-2395

44 Stawicki SP, Firstenberg MS, Lyaker MR, et al. Septic embolism in the intensive care unit. Int J Crit Illn Inj Sci 2013;3(01):58-63

45 Goswami U, Brenes JA, Punjabi GV, LeClaire MM, Williams DN. Associations and outcomes of septic pulmonary embolism. Open Respir Med J 2014;8:28-33

46 Plemmons RM, Dooley DP, Longfield RN. Septic thrombophlebitis of the portal vein (pylephlebitis): diagnosis and management in the modern era. Clin Infect Dis 1995;21(05):1114-1120

47 Centor RM. Expand the pharyngitis paradigm for adolescents and young adults. Ann Intern Med 2009;151(11):812-815

48 Mayne ES, Louw S. Good fences make good neighbors: human immunodeficiency virus and vascular disease. Open Forum Infect Dis 2019;6(11):ofz303

49 Lodigiani C, Iapichino G, Carenzo L, et al; Humanitas COVID-19 Task Force. Venous and arterial thromboembolic complications in COVID-19 patients admitted to an academic hospital in Milan, Italy. Thromb Res 2020;191:9-14

50 Paccoud O, Fontaine H, Bougnoux ME, Lortholary O, Suarez F, Lanternier F. Portal vein thrombosis as a long-term complication of chronic hepatosplenic candidiasis in an allogeneic haematopoietic stem-cell transplant recipient. Clin Microbiol Infect 2020; 26(07):967-968

51 Fardini Y, Wang X, Témoin S, et al. Fusobacterium nucleatum adhesin FadA binds vascular endothelial cadherin and alters endothelial integrity. Mol Microbiol 2011;82(06):1468-1480

52 Kasper DL, Sahani D, Misdraji J. Case records of the Massachusetts General Hospital. Case 25-2005. A 40-year-old man with prolonged fever and weight loss. N Engl J Med 2005;353(07):713-722

53 Murphy EC, Mörgelin M, Cooney JC, Frick IM. Interaction of bacteroides fragilis and Bacteroides thetaiotaomicron with the kallikrein-kinin system. Microbiology 2011;157(Pt 7): 2094-2105
54 Meda MS, Lopez AJ, Guyot A. Candida inferior vena cava filter infection and septic thrombophlebitis. Br J Radiol 2007;80(950): e48-e49

55 Maulat C, Lapierre L, Migueres I, Chaufour X, Martin-Blondel G, Muscari F. Caval replacement with parietal peritoneum tube graft for septic thrombophlebitis after hepatectomy: a case report. World J Hepatol 2019;11(01):133-137

56 Caccese R, Carfagna P, Pistilli N, Massetti AP, Falcone M, Venditti $M$. Candidal thrombophlebitis of central veins: case report and review. Med Mycol 2012;50(03):299-304

57 Rabah F, El-Banna N, Abdel-Baki M, et al. Postvaricella thrombosis-report of two cases and literature review. Pediatr Infect Dis J 2012;31(09):985-987

58 Driesen Y, Verweij M, De Maeseneer M, De Dooy J, Wojciechowski M, Van Den Akker M. Vascular complications of varicella: description of 4 Cases and a Review of Literature. Pediatr Infect Dis J 2015; 34(11):1256-1259

59 Khan R, Yasmeen A, Pandey AK, Al Saffar K, Narayanan SR. Cerebral venous thrombosis and acute pulmonary embolism following varicella infection. Eur J Case Rep Intern Med 2019;6(10):001171

60 Musselwhite LW, Sheikh V, Norton TD, et al. Markers of endothelial dysfunction, coagulation and tissue fibrosis independently predict venous thromboembolism in HIV. AIDS 2011;25(06): 787-795

61 Bai C, Ding J, Da Z, et al. Probable risk factors of internal jugular vein stenosis in Chinese patients-A real-world cohort study. Clin Neurol Neurosurg 2020;191:105678

62 Plastini T, Henry D, Dunleavy K. Ovarian vein thrombus: to treat or not to treat? Blood Adv 2017;1(15):1120-1123

63 Riva N, Donadini MP, Ageno W. Epidemiology and pathophysiology of venous thromboembolism: similarities with atherothrombosis and the role of inflammation. Thromb Haemost 2015;113 (06):1176-1183

64 Cassinelli G, Naggi A. Old and new applications of non-anticoagulant heparin. Int J Cardiol 2016;212(Suppl 1):S14-S21

65 Young E. The anti-inflammatory effects of heparin and related compounds. Thromb Res 2008;122(06):743-752

66 Di Nisio M, Wichers IM, Middeldorp S. Treatment for superficial thrombophlebitis of the leg. Cochrane Database Syst Rev 2018;2 (02):CD004982

67 Ungprasert P, Srivali N, Wijarnpreecha K, Charoenpong P, Knight EL. Non-steroidal anti-inflammatory drugs and risk of venous thromboembolism: a systematic review and meta-analysis. Rheumatology (Oxford) 2015;54(04):736-742

68 Malmberg S, Petrén S, Gunnarsson R, Sundvall PD, Hedin K. The likelihood that Fusobacterium necrophorum is linked to uncomplicated pharyngotonsillitis in primary care patients - a systematic with meta analysis. PROSPERO 2018:CRD4201810680

69 Miranda B, Aaron S, Arauz A, et al. The benefit of EXtending oral antiCOAgulation treatment (EXCOA) after acute cerebral vein thrombosis (CVT): EXCOA-CVT cluster randomized trial protocol. Int J Stroke 2018;13(07):771-774

70 Keshari RS, Silasi R, Popescu NI, et al. Fondaparinux pentasaccharide reduces sepsis coagulopathy and promotes survival in the baboon model of Escherichia coli sepsis. J Thromb Haemost 2020; 18(01):180-190

71 Peetermans M, Liesenborghs L, Peerlinck K, et al; Staphylothrombin Investigators. Targeting coagulase activity in Staphylococcus aureus bacteraemia: a randomized controlled single-centre trial of staphylothrombin inhibition. Thromb Haemost 2018;118(05): 818-829

72 Sexton TR, Zhang G, Macaulay TE, et al. Ticagrelor reduces thromboinflammatory markers in patients with pneumonia. JACC Basic Transl Sci 2018;3(04):435-449

73 Storey RF, James SK, Siegbahn A, et al. Lower mortality following pulmonary adverse events and sepsis with ticagrelor compared to clopidogrel in the PLATO study. Platelets 2014;25(07): 517-525 
74 Lancellotti P, Musumeci L, Jacques N, et al. Antibacterial activity of ticagrelor in conventional antiplatelet dosages against antibioticresistant gram-positive bacteria. JAMA Cardiol 2019;4(06): 596-599

75 Papareddy P, Rossnagel M, Doreen Hollwedel F, et al. A human antithrombin isoform dampens inflammatory responses and protects from organ damage during bacterial infection. Nat Microbiol 2019;4(12):2442-2455

76 Chen J, Li X, Li L, et al. Coagulation factors VII, IX and X are effective antibacterial proteins against drug-resistant Gram-negative bacteria. Cell Res 2019;29(09):711-724

77 Najem MY, Couturaud F, Lemarié CA. Cytokine and chemokine regulation of venous thromboembolism. J Thromb Haemost 2020;18(05):1009-1019

78 Ali RA, Gandhi AA, Meng $\mathrm{H}$, et al. Adenosine receptor agonism protects against NETosis and thrombosis in antiphospholipid syndrome. Nat Commun 2019;10(01):1916

79 Paciullo F, Momi S, Gresele P. PCSK9 in haemostasis and thrombosis: possible pleiotropic effects of PCSK9 inhibitors in cardiovascular prevention. Thromb Haemost 2019;119(03):359-367
80 Berger JM, Loza Valdes A, Gromada J, Anderson N, Horton JD. Inhibition of PCSK9 does not improve lipopolysaccharide-induced mortality in mice. J Lipid Res 2017;58(08):1661-1669

81 Heinzl MW, Resl M, Klammer C, Egger M, Dieplinger B, Clodi M. Proprotein convertase subtilisin/kexin type 9 (PCSK9) is not induced in artificial human inflammation and is not correlated with inflammatory response. Infect Immun 2020;88(03):e00842-19

82 Mahmoudpour SH, Jankowski M, Valerio L, et al. Safety of lowdose subcutaneous recombinant interleukin-2: systematic review and meta-analysis of randomized controlled trials. Sci Rep 2019;9(01):7145

83 Bochenek ML, Leidinger C, Rosinus NS, et al. Activated endothelial TGFß1 signaling promotes venous thrombus nonresolution in mice via endothelin-1: potential role for chronic thromboembolic pulmonary hypertension. Circ Res 2020;126(02):162-181

84 Laridan E, Martinod K, De Meyer SF. Neutrophil extracellular traps in arterial and venous thrombosis. Semin Thromb Hemost 2019; 45(01):86-93

85 Southwick FS. Septic thrombophlebitis of major dural venous sinuses. Curr Clin Top Infect Dis 1995;15:179-203 